\title{
HAND-FOOT-AND-MOUTH DISEASE EPIDEMIOLOGICAL STATUS AND RELATIONSHIP WITH METEOROLOGICAL VARIABLES IN GUANGZHOU, SOUTHERN CHINA, 2008-2012
}

Tiegang LI, Zhicong YANG, Xiangyi LIU, Yan KANG \& Ming WANG

\begin{abstract}
SUMMARY
Hand-foot-and-mouth disease (HFMD) is becoming one of the extremely common airborne and contact transmission diseases in Guangzhou, southern China, leading public health authorities to be concerned about its increased incidence. In this study, it was used an ecological study plus the negative binomial regression to identify the epidemic status of HFMD and its relationship with meteorological variables. During 2008-2012, a total of 173,524 HFMD confirmed cases were reported, 12 cases of death, yielding a fatality rate of 0.69 per 10,000 . The annual incidence rates from 2008 to 2012 were $60.56,132.44,311.40,402.76$, and 468.59 (per $100,000)$, respectively, showing a rapid increasing trend. Each $1{ }^{\circ} \mathrm{C}$ rise in temperature corresponded to an increase of $9.47 \%(95 \%$ CI $9.36 \%$ to $9.58 \%$ ) in the weekly number of HFMD cases, while a one hPa rise in atmospheric pressure corresponded to a decrease in the number of cases by $7.53 \%$ (95\% CI $-7.60 \%$ to $-7.45 \%)$. Similarly, each one percent rise in relative humidity corresponded to an increase of $1.48 \%$ or $3.3 \%$, and a one meter per hour rise in wind speed corresponded to an increase of $2.18 \%$ or $4.57 \%$, in the weekly number of HFMD cases, depending on the variables considered in the model. These findings revealed that epidemic status of HFMD in Guangzhou is characterized by high morbidity but low fatality. Weather factors had a significant influence on the incidence of HFMD.
\end{abstract}

KEYWORDS: Hand-foot-and-mouth disease (HFMD); Epidemiology; Meteorological variables; Correlation analysis.

\section{INTRODUCTION}

Hand-foot-and-mouth disease (HFMD) is a human syndrome caused by intestinal viruses of the picornaviridae family. The most common strains causing HFMD are coxsackie A virus and enterovirus 71 (EV71), resulting in major outbreaks across the world in the past three decades ${ }^{14}$. The clinical presentations of HFMD are characterized by fever and vesicular exanthema mostly in hands, feet and oral mucosa ${ }^{5}$. The disease is usually mild and self-limiting, but sometimes serious neurological and cardiopulmonary complications may occur in HFMD outbreaks, particularly when the causative virus is enterovirus $71^{27,32}$.

HFMD was first reported in New Zealand in 1957. Only small scale outbreaks have been reported from United States, Europe, Australia, Japan and Brazil in the first few decades. However, since 1997 the disease has conspicuously changed its behavior as noted in different Southeast Asian countries ${ }^{26}$. There was a sharp rise in incidence, severity, complications and even fatal outcomes that were almost unseen before that period. In 2008, a large wave of HFMD epidemics occurred in mainland China, Taiwan, Malaysia, Singapore and Hong Kong. In mainland China, epidemics started in Fuyang City, Anhui Province, resulting in 353 severe cases and 22 deaths, and then rapidly developed into a nationalscale epidemic, covering 28 provinces within three months with 345,159 reported $\operatorname{cases}^{36}$. To control the HFMD infections and decrease mortality from HFMD, the Chinese Ministry of Health (MOH) has listed HFMD as a notifiable Class-C communicable disease since $2008^{34}$.

As the largest trading city in Southern China-Guangzhou, here HFMD is becoming one of the extremely common airborne and contacttransmitting diseases. Despite preventive measures such as avoiding direct contact with infected patients, disinfection of viral contaminated items or premises, and good personal hygiene practices, have been strongly recommended and sometimes mandatorily implemented by the local government, the annual incidence of HFMD remained the highest of all reportable infectious diseases since 2008, leading public health authorities to be concerned about its increased incidence.

Currently, effective chemoprophylaxis or vaccination approaches for dealing with HFMD are still not available. One of the programs to prevent this disease concentrates on monitoring and predicting HFMD incidence. In recent decades, weather variables have been widely studied for their potential as early warning tools to fend off climate-sensitive infectious diseases such as dengue fever ${ }^{18}$, malaria ${ }^{19}$, and diarrheal disease $^{1}$. However, the relationship between meteorological variables and HFMD has been documented in some studies and the findings have been inconsistent ${ }^{12,20,21,30}$. For example, a Singapore study showed that 


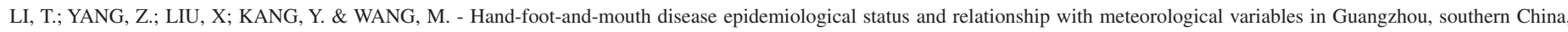
2008-2012. Rev. Inst. Med. Trop. Sao Paulo, 56(6): 533-9, 2014

weekly maximum temperature elevated HFMD incidence and a Hong Kong study also supported the positive association ${ }^{12,21}$, whereas another study in Japan found that the number of days per week of the average temperature above $25^{\circ} \mathrm{C}$ was negative associated with HFMD incidence ${ }^{30}$. In addition, a recent study in Japan found non-significant association between rainfall and HFMD, contrary to findings in Singapore ${ }^{12,20}$. Moreover, high wind speed was shown to be a risk factor for HFMD in the Hong Kong study ${ }^{21}$, but no other study supported these findings. Therefore, there is an urgent need to investigate such relationships which can help in the prediction of future occurrence and development of an early warning system of HFMD.

In this paper, it was used an ecological methodology to conduct an analysis on epidemiological characteristics of HFMD in Guangzhou during the period from 2008-2012, and compared these with the weather factors, in an effort to assess the relationship between meteorological variables and HFMD, and assist public health prevention and control measures.

\section{MATERIALS AND METHODS}

Study Area: Guangzhou is 7,434.4 Square kilometers in size, situated at north latitude $22^{\circ} 26^{\prime} \mathrm{N}$ to $23^{\circ} 56^{\prime} \mathrm{N}$ and at east longitude $112^{\circ} 57^{\prime} \mathrm{E}$ to $114^{\circ} 3^{\prime} \mathrm{E}$, with over 7.94 million registered inhabitants and 4.76 million floating population (from 2010 census data). It crosses the Tropic of Cancer, and the climate is characterized as humid subtropical climate influenced by the Asian monsoon. Summers are wet with high temperatures and a high humidity index. Winters are mild, dry and sunny. The annual mean temperature ranges from $18{ }^{\circ} \mathrm{C}$ to $25^{\circ} \mathrm{C}$. The annual rainfall is typically between $1,500 \mathrm{~mm}$ and 2,000 $\mathrm{mm}$ (Fig. 1).

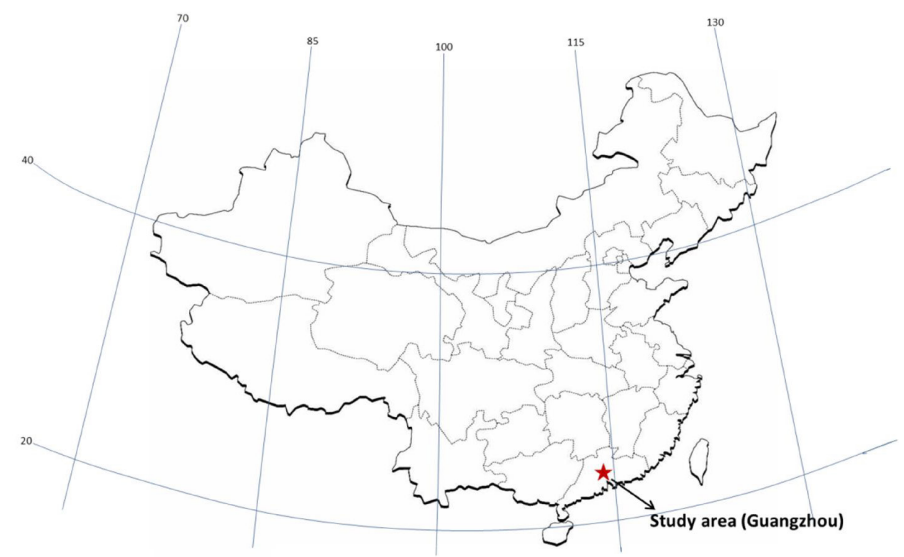

Fig. 1 - Geographic location of the study area (Guangzhou) on the map.

Surveillance data of HFMD: In this study, data from HFMD cases in Guangzhou were obtained during the period between January $1^{\text {st }}, 2008$ and December 31 ${ }^{\text {st }}, 2012$, from National Notifiable Disease Report System (NNDRS). In China, all cases of HFMD were diagnosed according to the unified diagnostic criteria issued by the Chinese Ministry of Health. Once physicians diagnose suspected or confirmed HFMD cases, they must report these cases to Guangzhou Centers for Disease Control and Prevention (GZCDC) via NNDRS. For a patient's illness to meet the case definition of HFMD clinical signs (fever, papules and herpetic lesions on the hands or feet, rashes on the buttocks or knees, inflammatory flushing around the rashes and little fluid in blisters, sparse herpetic lesions on oral mucosa, etc.) must be present and samples should be taken for laboratory confirmation (4-fold rise in antibody titer, antigen detected in blood, PCR- detected samples from throat, fluids from blisters and stools). A standard form was adopted by local physicians and epidemiologist to collect individual information on each HFMD case, including age, address, onset date, occupation, diagnosis, and laboratory test results. The reporting of routine cases is made by hospitals via NNDRS within 24 hours. The scattered children were defined as children who migrated from other cities (usually from underdeveloped regions), without permanent housing in Guangzhou, and who do not attend school even though they were at school age.

Meteorological data: Simultaneous meteorological data, including average daily temperature (in degrees Celsius), relative humidity (as a percentage), atmospheric pressure (in $\mathrm{hPa}$ ), and wind velocity (in meters per second) were obtained from the documentation of the Guangzhou Meteorological Bureau (GZMB). The weather data was measured at a fixed-site station located in the central district of Guangzhou.

Data analysis: Descriptive statistics, such as percentages, means, and $95 \%$ confidence intervals, were calculated. $\chi 2$ test and/or Fisher exact test were/was used to compare proportions of different groups. A negative binomial multivariable regression was used to explore the relationship between meteorological variables and HFMD. Negative binomial distribution is a Poisson distribution with an extra-dispersion term, which acts as a random effect that subjects the Poisson means to an additional variation that has a gamma distribution. Given the fact that the data were over-dispersed, it was chosen a negative binomial distribution model rather than the Poisson model. The cases are the incidence of HFMD per 100,000 inhabitants grouped by week of onset. The meteorological variables were calculated by weekly average. A preliminary analysis was conducted through Pearson's correlation coefficient (' $r$ ') matrix within meteorological variables. This indicated that the model constructed using both temperature and atmospheric pressure at the same time suffered from collinearity problems, because the two variables showed strong negative correlation $(\mathrm{r}=-0.83, p<0.01)$. Thus, two separate negative binomial regression models were carried out: the first included average temperature but no atmospheric pressure, while the second included atmospheric pressure but no temperature. Both models included additionally relative humidity, wind speed, and year as independent variables. To quantify the effects of meteorological variables, the influences $\left(e^{\beta}-1\right)$ were computed, which virtually correspond to the percent increase. The ln of the predicted rate was used to examine the linearity between predictor and continuous variable. In addition, a residual diagnosis was also carried out. The residual was checked using the Pearson goodness of fit test. These analyses were performed using SAS (V.8.01, SAS Institute, Cary, New Jersey, USA). $p$ values $<0.05$ were considered as statistically significant.

\section{RESULTS}

From January $1^{\text {st }}, 2008$ to December $31^{\text {st }}, 2012$, a total of 173,524 HFMD confirmed cases were reported in Guangzhou, of which $63.85 \%$ $(110,799)$ were male patients and $36.15 \%(62,725)$ were female patients. 12 cases died between the ages of one and 14, yielding a fatality rate of 0.69 per 10,000 . The greatest number of cases was in the age group between zero and five years, which accounted for $93.82 \%(162,798)$ of the total cases. By occupation, the majority of cases were scattered children, 
which accounted for $73.01 \%(126,695)$ of all cases. Annual incidence rates from 2008 to 2012 were $60.56,132.44,311.40,402.76$, and 468.59 (per 100,000), respectively. It is important to stress that in 2012, a total of 60,155 HFMD confirmed cases were reported, which was 8.9 times the number reported in 2008 (6,754 cases) (Fig. 2).

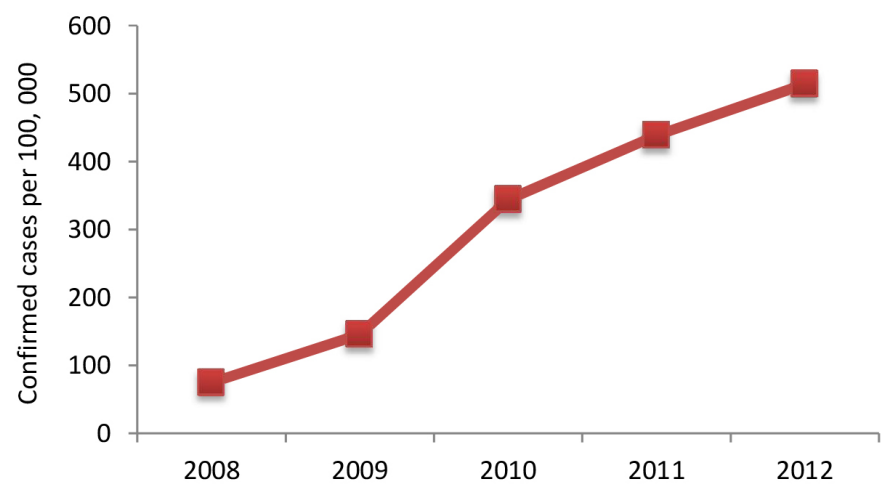

Fig. 2 - Annual disturbance of HFMD confirmed cases per 100,000 in Guangzhou, Southern China, 2008-2012.

Monthly changes in the number of cases showed HFMD cases were detected throughout the year. A sharp peak in the number of cases occurred in May-July, $47.17 \%$ of all cases were reported during this period. A small peak occurred in September-October, the number of cases reported during this period accounted for $17.60 \%$ of total cases (Fig. 3).

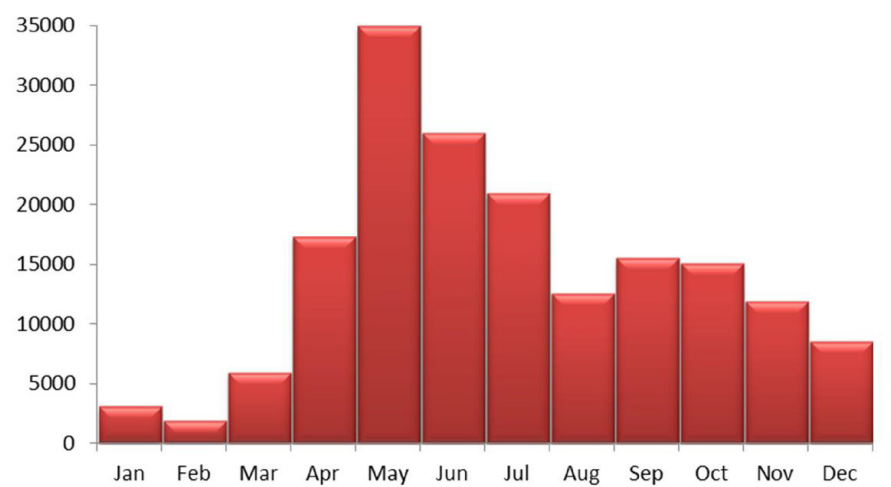

Fig. 3 - Monthly disturbance of HFMD confirmed cases in Guangzhou, Southern China.

Overall, the main pathogens causing HFMD in Guangzhou during the period from 2008-2012 were enterovirus 71 (EV71) and coxsackievirus A16 (CA16), which accounted for $61.29 \%$ of the total causative viruses. Figure 4 detailed the yearly disturbance of pathogens causing HFMD in Guangzhou. It is important to note that the proportion of EV71 was $44.98 \%$ in $2008,30.587 \%$ in $2009,25.79 \%$ in $2010,21.36 \%$ in 2011 , and $24.76 \%$ in 2012 , respectively, which showed a significance declining trend over the years (Trend $\chi^{2}=76.63, p<0.001$ ).

During the study period, the minimum and maximum temperatures were $1.8{ }^{\circ} \mathrm{C}$ and $38.6{ }^{\circ} \mathrm{C}$, respectively, and the average temperature was $22.23{ }^{\circ} \mathrm{C}$. The relative humidity ranged from $25 \%$ to $99 \%$, with an average of $73.94 \%$. The atmospheric pressure ranged from $987.4 \mathrm{hPa}$ to 1026.6hPa, with an average of $1006.77 \mathrm{hPa}$. The wind speed ranged from $0.4 \mathrm{~m} / \mathrm{s}$ to $9.1 \mathrm{~m} / \mathrm{s}$, with an average of $1.90 \mathrm{~m} / \mathrm{s}$ (Fig. 5).

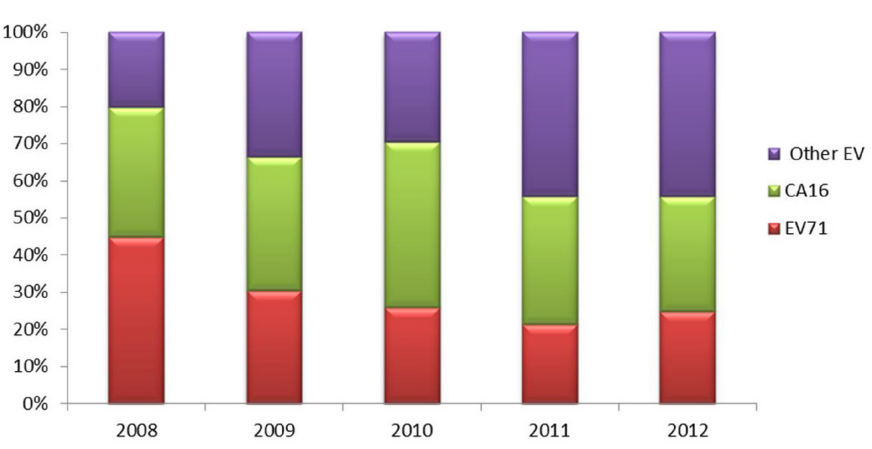

Fig. 4 - Yearly disturbance of pathogens causing HFMD in Guangzhou, Southern China, 2008-2012.

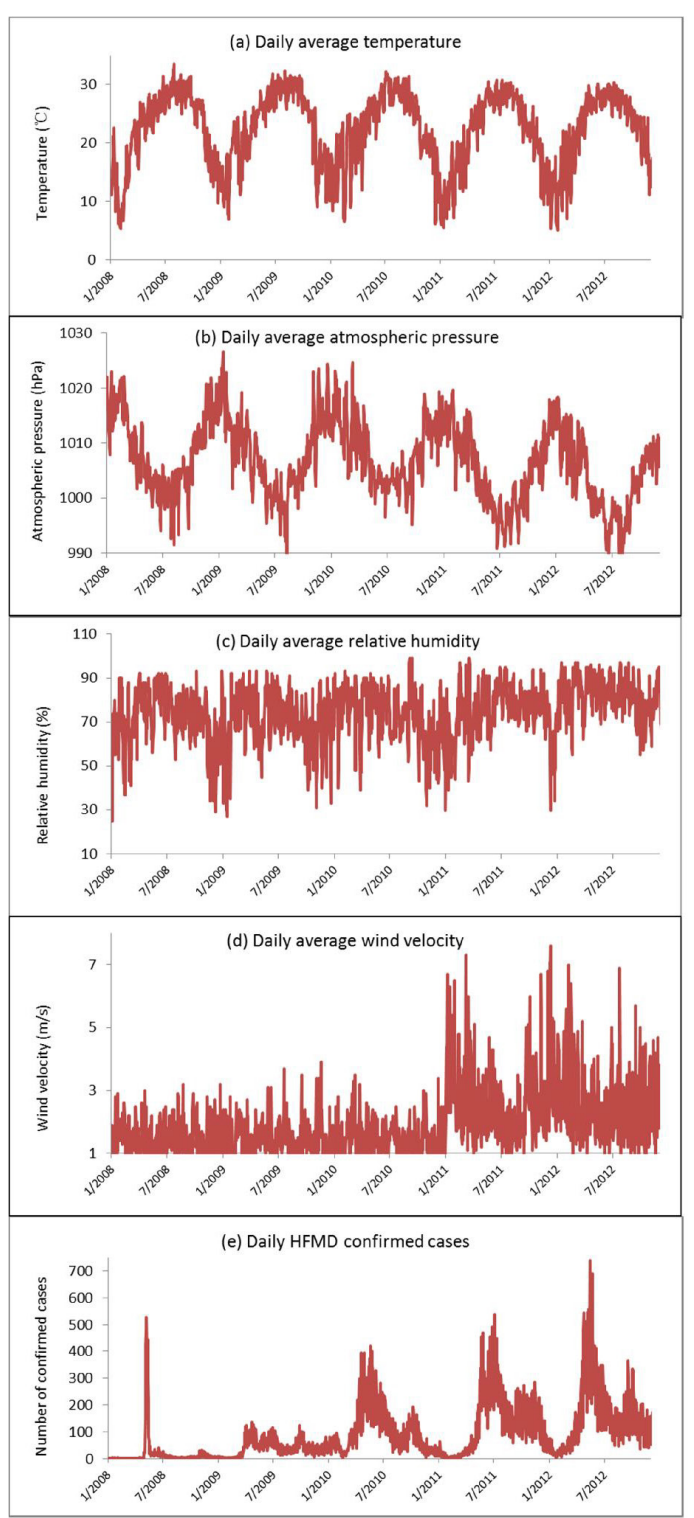

Fig. 5 - Daily disturbance of a) average temperature; b) average atmospheric pressure; c) average relative humidity; d) average wind speed; e) HFMD confirmed cases in Guangzhou, Southern China, 2008-2012. 


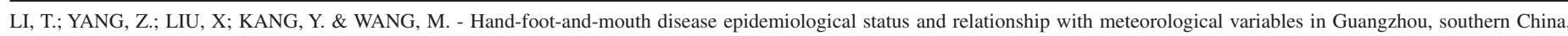
2008-2012. Rev. Inst. Med. Trop. Sao Paulo, 56(6): 533-9, 2014.

The correlations between independent variables revealed a strong correlation $(\mathrm{r}=-0.83, p<0.01)$ between average temperature and atmospheric pressure (Table 1). Therefore, to avoid collinearity problems, it was decided to explore the relationship of temperature and atmospheric pressure in HFMD cases by using two different models, including either temperature or atmospheric pressure together with all other predictors. In the two models, temperature $(p<0.01)$ and atmospheric pressure $(p<0.01)$ were highly significant; wind speed, relative humidity, and year were also significant in both models (all $p<0.05)$. After adjusting the "year", every $1{ }^{\circ} \mathrm{C}$ rise in temperature corresponded to an increase of $9.47 \%$ (95\% CI $9.36 \%$ to $9.58 \%$ ) in the weekly number of HFMD cases, while a $1 \mathrm{hPa}$ rise in atmospheric pressure corresponded to a decrease in the number of cases by $7.53 \%$ (95\% CI $-7.60 \%$ to $-7.45 \%)$. Similarly, every one percent rise in relative humidity corresponded to an increase of $1.48 \%$ or $3.3 \%$, and a one meter per hour rise in wind speed corresponded to an increase of $2.18 \%$ or $4.57 \%$, in the weekly number of HFMD cases, depending on the variables considered in the model (Table 2). The Pearson goodness of fit test for both models indicated $p>0.05$.

\section{DISCUSSION}

It was found that, from 2008 to 2012, the incidence rate of HFMD in Guangzhou showed a rapid increasing trend, this is consistent with studies from most cities in China ${ }^{31}$. However, despite the enormous numbers of cases, the overall fatality rate of HFMD was 0.69 per 10,000, which was significantly lower than in Cambodia ${ }^{4}$, Vietnam ${ }^{15}$, and previous report from other regions of China ${ }^{23}$. These indicated that HFMD in Guangzhou was becoming more contagious than before, and the present epidemic situation of HFMD was characterized by high morbidity, but low fatality. A possible explanation for this might be due to the fact that the viruses causing HFMD have been changing recently in the last few years in Guangzhou. As indicated by this study, the proportion of causative viruses, identified as EV71, decreased from $45 \%$ in 2008 to $25 \%$ in 2012. Many previous studies have proved that EV71associated HFMD usually had severe clinical syndromes, such as acute flaccid paralysis, brainstem encephalitis, rapid fatal pulmonary edema, and hemorrhage ${ }^{13}$, which more frequently resulted in patients' death. By contrast, CA16 and other etiologic agent-associated HFMD had a

Table 1

Pearson's correlation coefficient ('r') matrix of meteorological variables in Guangzhou, Southern China, 2008-2012

\begin{tabular}{|c|c|c|c|c|}
\hline & Average temperature & Relative humidity & Atmospheric pressure & Wind velocity \\
\hline Average temperature & 1.00 & - & - & - \\
\hline Relative humidity & $0.24(p<0.01)$ & 1.00 & - & - \\
\hline Atmospheric pressure & $-0.83(p<0.01)$ & $-0.52(p<0.01)$ & 1.00 & - \\
\hline Wind velocity & $-0.33(p<0.01)$ & $0.07(p=0.27)$ & $-0.03(p=0.60)$ & 1.00 \\
\hline
\end{tabular}

Table 2

Negative binomial regression model of meteorological factors associated with risk of HFMD incidence

$\beta \quad$ S. E. $\quad P \quad \begin{gathered}\left(\mathrm{e}^{\beta}-1\right)^{*} 100= \\ \text { percent increase }(\%)\end{gathered} \frac{\begin{array}{c}95 \% \text { Confidence Interval for percent } \\ \text { increase }(\%)\end{array}}{\text { Lower boundary } \quad \text { Upper boundary }}$

(A)

$\begin{array}{lcccccc}\text { (Intercept) } & 83.59 & 0.44 & <0.01 & - & - & - \\ \text { Relative humidity } & 0.01 & 0.00 & <0.01 & 1.48 & 1.42 & -7.55 \\ \text { Atmospheric pressure } & -0.08 & 0.00 & <0.01 & -7.53 & 2.18 & 2.11 \\ \text { Wind velocity } & 0.02 & 0.00 & 0.01 & 53.04 & 26.35 & 85.36 \\ \text { Year } & 0.43 & 0.98 & <0.01 & & \end{array}$

(B)

\begin{tabular}{lllllll} 
(Intercept) & 1.01 & 0.03 & $<0.01$ & - & - & - \\
Relative humidity & 0.03 & 0.00 & $<0.01$ & 3.30 & 3.24 & 9.36 \\
Average temperature & 0.09 & 0.00 & $<0.01$ & 4.47 & 9.58 \\
Wind velocity & 0.04 & 0.00 & $<0.01$ & 4.57 & 4.50 & 2.64 \\
Year & 0.39 & 0.98 & $<0.01$ & 48.14 & 79.59 \\
\hline
\end{tabular}

Negative binomial regression model for weekly HFMD incidence without average temperature (A) and without atmospheric pressure (B). 


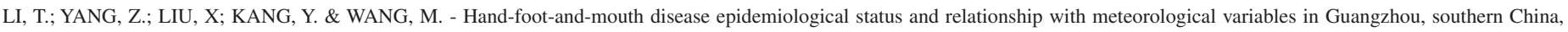
2008-2012. Rev. Inst. Med. Trop. Sao Paulo, 56(6): 533-9, 2014.

milder outcome and a much lower incidence of severe complications ${ }^{17}$.

Inconsistent with the situation in Mongolia and Northern China ${ }^{35}$ where only a single incidence peak of HFMD was observed in July, the current study showed that two incidence peaks of HFMD were detected in Guangzhou, the higher one occurring in May-July and the lower one occurred in September-October. These two peaks, all reached approximately one month earlier than in some other Asian countries, such as Japan ${ }^{24}$ and Vietnam ${ }^{29}$. In addition, some HFMD confirmed cases were found, and were more heavily male than female, and the higher number of cases was in the 0-5 age group. These are similar to the findings from Taiwan ${ }^{7}$, Singapore ${ }^{2}$, and other areas ${ }^{3,20}$. However, these results implied that the same or even more attention should be given to scattered children, which has become the largest HFMD infected group in Guangzhou. In China, they are called "scattered children", because the majority of this group of children comes from low-income families, their parents usually do not have enough money to send them to kindergarten or nursery. They usually live in crowded places, with poor sanitation, low health risk awareness, and lack of access to health education. It has been reported that compared to the other group, the scattered children had higher incidence in many infectious diseases, such as Bacillary dysentery, infectious diarrhe $\mathrm{a}^{33}$, and hepatitis $\mathrm{A}^{16}$. Therefore, more effort should be employed to enhance health education and monitor the scattered children.

Weather factors such as temperature and humidity have been proved to have significant influence on occurrence and transmission of some infectious diseases. For example, in Switzerland, higher water vapor pressure and heat were found to be associated with a higher risk of community-acquired Legionnaires' disease ${ }^{8}$; in Botswana, the elevation of annual minimum temperature was considered as the critical factor for continuous ascent in the number of diarrheal disease reported during the period from 1974-2003 ${ }^{1}$. The current study, which was conducted in Guangzhou, demonstrated that high temperature and high humidity presented higher risk of HFMD infection. These findings are consistent with a previous study in Tokyo, Japan, which suggested that higher temperature and humidity might influence the increase of HFMD incidence observed between 1999 and $2002^{30}$, and with the findings of a more recent study in Hong Kong, indicating that HFMD consultation rates were positively associated to temperature and humidity ${ }^{21}$. In Taiwan, CHANG et al. reported that EV71 infection was most highly correlated with temperature and relative humidity in the period that was likely to precede the infection ${ }^{6}$. Furthermore, it was also found that atmospheric pressure was inversely associated to HFMD incidence in the same week. Similar findings were also observed in the north of $\mathrm{China}^{26}$, which indicated that the air pressure showed an opposite behavior from the incidence distribution of HFMD. However, no literature has been published yet revealing the underlying mechanism. A possible explanation for this may be due to the fact that low atmospheric pressure could weaken the power of the human immune system or of organisms ${ }^{22}$. For example, DANET et al. reported that a 10-mbar decrease in atmospheric pressure was associated to a $12 \%$ increase in coronary disease incidence rates ${ }^{9}$; STYRA et al. found that the correlation between atmospheric pressure decrease and increase of cardiovascular disease (CVD) in 1-2 days and on the same day was $25-44 \%{ }^{28}$.

As far as the author knows, the present report is first to investigate the effect of wind speed on HFMD incidence in Southern China. It was found that every meter per second rise in wind speed may lead to an increase of $2.18 \%$ or $4.57 \%$ in the weekly number of HFMD cases. This result was contrary to expectations and must be interpreted with caution, because previous studies have showed that wind speed could reduce the risk of infection of many diseases. For example, DUNN et al. reported that high wind speed was associated with significant low incidence of Legionnaires' disease in UK ${ }^{11}$. ROSA-FREITAS et al. found that the number of reported dengue cases was statistically and significantly lower in a high wind speed area than in a low wind speed area ${ }^{25}$. Therefore, further studies, which take these variables into account, will need to be undertaken.

Some methodological limitations must be acknowledged in this study: the incubation period of 3-7 days for every case cannot be determined exactly, and this is the reason why it was chosen to use weekly aggregated HFMD data and weekly average meteorological data. The direction of these approximations, however, is likely to be random, suggesting that these risk estimates are reliable. Moreover, because this investigation is an ecological study - an observational epidemiological study in which the unit of analysis is a population rather than an individual, one cannot exclude the fact that some potential confounding variables could not be identified and considered. Although the impact of climate was emphasized, other factors such as host susceptibility, exposure history, preventive measures and intervening variables also probably existed and influenced the HFMD occurrence by some way. Therefore, more studies, which take these variables into account, will need to be undertaken. Of course, some findings in the current study require replication, especially in different areas with diverse weather patterns. On the other hand, one must acknowledge that this conclusion is based on the Guangzhou's weather pattern; replication of the similar study may reach the opposite conclusion in the area, with a completely different weather pattern to the area which was studied.

\section{CONCLUSIONS}

Taken together, despite these limitations, it was reported that the epidemic status of HFMD in Guangzhou was characterized by high morbidity, but low fatality. Males, aged 0-5 years, and scattered children seemed more susceptible to HFMD infection. Weather factors had significant influence on HFMD. A rise in average temperature, relative humidity, and wind speed may increase the risk of HFMD infection, while an increase in atmospheric pressure may reduce the risk of HFMD infection. These findings provided preliminary, but fundamental information that may be useful for a better understanding of epidemic trends of HFMD and to develop an early warning system.

\section{RESUMO}

\section{Situação epidemiológica e a relação com variáveis meteorológicas da HFMD em Guangzhou, sul da China, 2008-2012}

A doença de mão-pé-e-boca (HFMD) está se tornando doença extremamente comum transmitida pelo ar e contato em Guangzhou, sul da China, levando preocupação às autoridades de saúde pública acerca da sua incidência aumentada. Neste estudo foi usada parte ecológica e regressão binomial negativa para identificar o status epidêmico da HFMD e sua relação com variáveis meteorológicas. Durante 2008-2012 um total de 173.524 casos confirmados de HFMD foram apresentados, 12 com morte, elevando o índice de fatalidade a 0,69 por 10.000 . As incidências 
LI, T.; YANG, Z.; LIU, X; KANG, Y. \& WANG, M. - Hand-foot-and-mouth disease epidemiological status and relationship with meteorological variables in Guangzhou, southern China, 2008-2012. Rev. Inst. Med. Trop. Sao Paulo, 56(6): 533-9, 2014.

anuais de 2008 a 2010 foram 60,56, 132,44, 311,40, 402,76 e 468,59 por 100.000, respectivamente, mostrando tendência de rápido aumento. Cada $1{ }^{\circ} \mathrm{C}$ de aumento da temperatura correspondeu a aumento de $9,47 \%(95 \%$ CI $9,36 \%$ a $9,58 \%$ ) no número semanal de casos de HFMD, enquanto a $1 \mathrm{hPa}$ de aumento da pressão atmosférica correspondeu a decréscimo no número de casos de 7,53\% (95\% CI - 7,60\% a - 7,45\%). De maneira semelhante cada aumento de $1 \%$ na humidade relativa correspondeu a aumento de $1,48 \%$ ou $3,3 \%$ e a um aumento de 1 metro por hora na velocidade do vento correspondeu a um aumento de $2,18 \%$ ou $4,57 \%$, no número de casos semanais de HFMD, dependendo das variáveis consideradas no modelo. Estes achados revelaram que o status epidêmico do HFMD em Guangzhou é caracterizado por alta morbidade, mas baixa fatalidade. Fatores referentes ao tempo tiveram influência significante na incidência do HFMD.

\section{ACKNOWLEDGEMENTS}

All enrollees who participated in the study are appreciated. We wish to give special thanks to the public unit coordinators and nurses in hospitals in Guangzhou.

\section{AUTHORS' CONTRIBUTIONS}

To the people who conceived and designed the study: Zhicong Yang, Ming Wang; collected the data: Xiangyi Liu, Yan Kang; analyzed the data: Tiegang Li; contributed reagents/materials/analysis tools: Zhicong Yang, Ming Wang; wrote the paper: Tiegang Li, Zhicong Yang, Ming Wang.

\section{FUNDING}

This work was supported by the Research Fund from the Health Bureau of Guangzhou (grant number 20131A011104, 20141A11053), Science and Technology Bureau of Guangzhou (grant number 2012Y2-00020), Guangdong Science and Technology Program (grant number 2012B040304002), The Project For Key Medicine Discipline Construction Of Guangzhou Municipality (grant number 2013-2015-07). The founders had no role in the study design, data collection and analysis, decision to publish, or preparation of the manuscript.

\section{CONFLICTS OF INTEREST}

None declared.

\section{ETHICAL APPROVAL}

This study was approved by the ethics committee of Guangzhou Center for Disease Control and Prevention (GZCDC).

\section{REFERENCES}

1. Alexander KA, Carzolio M, Goodin D, Vance E. Climate change is likely to worsen the public health threat of diarrheal disease in Botswana. Int J Environ Res Public Health. 2013; 10:1202-30

2. Ang LW, Koh BK, Chan KP, Chua LT, James L, Goh KT. Epidemiology and control of hand, foot and mouth disease in Singapore, 2001-2007. Ann Acad Med Singapore. 2009;38:106-12.
3. Bahri O, Rezig D, Nejma-Oueslati BB, Yahia AB, Sassi JB, Hogga N, et al. Enteroviruses in Tunisia: virological surveillance over 12 years (1992-2003). J Med Microbiol. 2005;54:63-9.

4. Biswas T. Enterovirus 71 causes hand, foot and mouth disease outbreak in Cambodia. Natl Med J India. 2012; 25:316.

5. Blomqvist S, Klemola P, Kaijalainen S, Paananen A, Simonen ML, Vuorinen T, et al. Co-circulation of coxsackieviruses A6 and A10 in hand, foot and mouth disease outbreak in Finland. J Clin Virol. 2010;48:49-54.

6. Chang HL, Chio CP, Su HJ, Liao CM, Lin CY, Shau WY, et al. The association between enterovirus 71 infections and meteorological parameters in Taiwan. PLoS One. 2012;7:e46845.

7. Chen KT, Chang HL, Wang ST, Cheng YT, Yang JY. Epidemiologic features of handfoot-mouth disease and herpangina caused by enterovirus 71 in Taiwan, 1998-2005. Pediatrics. 2007;120:e244-52

8. Conza L, Casati S, Limoni C, Gaia V. Meteorological factors and risk of communityacquired Legionnaires' disease in Switzerland: an epidemiological study. BMJ Open. 2013;3(3):e002428.

9. Danet S, Richard F, Montaye M, Beauchant S, Lemaire B, Graux C, et al. Unhealthy effects of atmospheric temperature and pressure on the occurrence of myocardial infarction and coronary deaths. A 10-year survey: the Lille-World Health Organization MONICA project (Monitoring trends and determinants in cardiovascular disease). Circulation. 1999;100:E1-7.

10. Deng T, Huang Y, Yu S, Gu J, Huang C, Xiao G, et al. Spatial-temporal clusters and risk factors of hand, foot, and mouth disease at the district level in Guangdong province, China. PLoS One. 2013;8:e56943.

11. Dunn CE, Rowlingson B, Bhopal RS, Diggle P. Meteorological conditions and incidence of Legionnaires' disease in Glasgow, Scotland: application of statistical modelling. Epidemiol Infect. 2013;141:687-96.

12. Hii YL, Rocklov J, Ng N. Short term effects of weather on hand, foot and mouth disease. PLoS One. 2011;6:e16796.

13. Ho M, Chen ER, Hsu KH, Twu SJ, Chen KT, Tsai SF, et al. An epidemic of enterovirus 71 infection in Taiwan. Taiwan Enterovirus Epidemic Working Group. N Engl J Med. 1999;341:929-35.

14. Hosoya M, Kawasaki Y, Sato M, Honzumi K, Kato A, Hiroshima T, et al. Genetic diversity of enterovirus 71 associated with hand, foot and mouth disease epidemics in Japan from 1983 to 2003. Pediatr Infect Dis J. 2006;25:691-4.

15. Khanh TH, Sabanathan S, Thanh TT, Thoa LP, Thuong TC, Hang V, et al. Enterovirus 71-associated hand, foot, and mouth disease, Southern Vietnam, 2011. Emerg Infect Dis. 2012;18:2002-5.

16. Li H, Zhang XS, An J. Evaluation on the effect of immunization and safety of live attenuated and inactivated hepatitis A vaccine in China. Zhonghua Liu Xing Bing Xue Za Zhi. 2013;34:24-7.

17. Li L, He Y, Yang H, Zhu J, Xu X, Dong J, et al. Genetic characteristics of human enterovirus 71 and coxsackievirus A16 circulating from 1999 to 2004 in Shenzhen, People's Republic of China. J Clin Microbiol. 2005;43:3835-9.

18. Li T, Yang Z, Luo L, Di B, Wang M. Dengue fever epidemiological status and relationship with meteorological variables in Guangzhou, Southern China, 2007-2012. Biomed Environ Sci. 2013;26:994-7.

19. Li T, Yang Z, Wang M. Temperature, relative humidity and sunshine may be the effective predictors for occurrence of malaria in Guangzhou, southern China, 2006-2012. Parasit Vectors. 2013;6:155. 


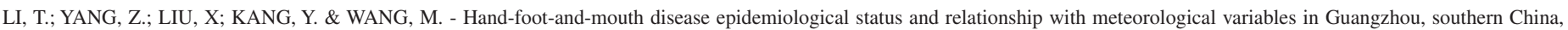
2008-2012. Rev. Inst. Med. Trop. Sao Paulo, 56(6): 533-9, 2014.

20. Lin TY, Chang LY, Huang YC, Hsu KH, Chiu CH, Yang KD. Different proinflammatory reactions in fatal and non-fatal enterovirus 71 infections: implications for early recognition and therapy. Acta Paediatr. 2002;91:632-5.

21. Ma E, Lam T, Wong C, Chuang SK. Is hand, foot and mouth disease associated with meteorological parameters? Epidemiol Infect. 2010;13:1779-88.

22. Maes M, De Meyer F. Relationships of climatic data to immune and hematologic variables in normal human. Neuro Endocrinol Lett. 2000;21:127-36.

23. Mao LX, Wu B, Bao WX, Han FA, Xu L, Ge QJ, et al. Epidemiology of hand, foot, and mouth disease and genotype characterization of Enterovirus 71 in Jiangsu, China. J Clin Virol. 2010; 49:100-4

24. Onozuka D, Hashizume M. The influence of temperature and humidity on the incidence of hand, foot, and mouth disease in Japan. Sci Total Environ. 2011;410-411:119-25.

25. Rosa-Freitas MG, Schreiber KV, Tsouris P, Weimann ET, Luitgards-Moura JF. Associations between dengue and combinations of weather factors in a city in the Brazilian Amazon. Rev Panam Salud Publica. 2006;20:256-67.

26. Sarma N. Hand, foot, and mouth disease: current scenario and Indian perspective. Indian J Dermatol Venereol Leprol. 2013;79:165-75.

27. Solomon T, Lewthwaite P, Perera D, Cardosa MJ, McMinn P, Ooi MH. Virology, epidemiology, pathogenesis, and control of enterovirus 71. Lancet Infect Dis 2010;10:778-90

28. Styra D, Usovaite A, Damauskaite J, Juozulynas A. Leaps in cardiovascular disease after a decrease of hard cosmic ray flux and atmospheric pressure in Vilnius city in 2004-2007. Int J Biometeorol. 2009;53:471-7.
29. Tu PV, Thao NT, Perera D, Huu TK, Tien NT, Thuong TC, et al. Epidemiologic and virologic investigation of hand, foot, and mouth disease, southern Vietnam, 2005 Emerg Infect Dis. 2007;13:1733-41.

30. Urashima M, Shindo N, Okabe N. Seasonal models of herpangina and hand-foot-mouth disease to simulate annual fluctuations in urban warming in Tokyo. Jpn J Infect Dis. $2003 ; 13: 48-53$

31. Wang JF, Xu CD, Tong SL, Chen HY, Yang WZ. Spatial dynamic patterns of hand-footmouth disease in the People's Republic of China. Geospat Health. 2013;7:381-90.

32. Weng KF, Chen LL, Huang PN, Shih SR. Neural pathogenesis of enterovirus 71 infection. Microbes Infect. 2010;12:505-10.

33. Ye HC, Liu YH. Epidemiological study of rotavirus diarrhea in Beijing area from 2010 to 2012. Zhonghua Shi Yan He Lin Chuang Bing Du Xue Za Zhi. 2012;26:432-4.

34. Zeng M, Li YF, Wang XH, Lu GP, Shen HG, Yu H, et al. Epidemiology of hand, foot, and mouth disease in children in Shanghai 2007-2010. Epidemiol Infect. 2012;140:1122 30

35. Zhang J, Sun J, Chang Z, Zhang W, Wang Z, Feng Z. Characterization of hand, foot, and mouth disease in China between 2008 and 2009. Biomed Environ Sci. 2011;24:214 21.

36. Zhang Y, Zhu Z, Yang W, Ren J, Tan X, Wang Y, et al. An emerging recombinant human enterovirus 71 responsible for the 2008 outbreak of hand foot and mouth disease in Fuyang city of China. Virol J. 2010;7:94.

Received: 21 June 2013

Accepted: 21 March 2014 